\title{
Long-term tolerability of topical diclofenac sodium I\% gel for osteoarthritis in seniors and patients with comorbidities
}

This article was published in the following Dove Press journal:

Clinical Interventions in Aging

19 November 2012

Number of times this article has been viewed

\author{
John H Peniston' \\ Morris S Gold ${ }^{2}$ \\ Matthew S Wieman ${ }^{3}$ \\ Lawrence K Alwine ${ }^{4}$ \\ 'Feasterville Family Health Care \\ Center, Feasterville, PA, ${ }^{2}$ Clinical \\ Research and Biostatistics, Novartis \\ Consumer Health Inc, Parsippany, NJ, \\ ${ }^{3}$ Medical Affairs, Endo Pharmaceuticals \\ Inc, Chadds Ford, PA, ${ }^{4}$ Downingtown \\ Family Medicine, Downingtown, PA, \\ USA
}

Background: Adverse events associated with nonsteroidal anti-inflammatory drugs (NSAIDs) used to treat knee and hand osteoarthritis may be more frequent in certain patient populations. Topical NSAIDs, such as diclofenac sodium 1\% gel (DSG), have equivalent efficacy and fewer adverse events compared with oral NSAIDs. This post hoc analysis assessed the long-term tolerability of DSG in elderly patients and patients with an elevated risk of gastrointestinal, cardiovascular, and renal adverse events.

Methods: Patients $\geq 35$ years of age with knee osteoarthritis applied DSG (4 g) to one or both knees for 12 weeks during either of two primary studies and for 9 months during a long-term extension study. Other patients entered the long-term extension study directly and applied DSG for 12 months. Safety was assessed by reported adverse events. Subpopulations were defined based on age, or the comorbidities of hypertension, type 2 diabetes mellitus, and cerebrovascular or cardiovascular disease.

Results: The safety population consisted of 947 patients who received at least one dose of DSG during the primary or extension study. Patients aged $<65$ years $(68.2 \%)$ and $\geq 65$ years $(67.2 \%)$ experienced any adverse event at similar rates. The percentage of patients who experienced any adverse event was similar between patients with and without hypertension $(65.5 \%$ versus $69.7 \%$, respectively), type 2 diabetes mellitus ( $64.0 \%$ versus $68.2 \%)$, or cerebrovascular or cardiovascular disease (61.9\% versus $68.5 \%$ ). Among the 15 patients with all three comorbidities, the percentage of patients with any adverse event (53.3\%) was less than that of patients who did not have all three comorbidities $(68.0 \%)$.

Conclusion: These results suggest that long-term DSG treatment is safe in patient subpopulations with an elevated risk of NSAID-related adverse events, such as the elderly and those with the comorbidities of hypertension, type 2 diabetes mellitus, and cerebrovascular or cardiovascular disease.

Keywords: diclofenac, nonsteroidal anti-inflammatory drugs, osteoarthritis, topical analgesic

\section{Introduction}

Nonsteroidal anti-inflammatory drugs (NSAIDs) are commonly used for the treatment of osteoarthritis of the knee and hand. ${ }^{1,2}$ However, use of NSAIDs has frequently been accompanied by the occurrence of gastrointestinal, ${ }^{3-5}$ cardiovascular, ${ }^{6,7}$ and renal $^{8-10}$ adverse events, which may be more frequent in the elderly population and in people with comorbid conditions, such as hypertension, type 2 diabetes mellitus, and cerebrovascular or cardiovascular disease. ${ }^{9,11}$ Oral NSAIDs should be used at the lowest effective dose in patients with osteoarthritis to minimize the potential
Correspondence: John H Peniston Feasterville Family Health Care Center, 1665 Bustleton Pike, Feasterville,

PA 19053, USA

Tel +I 2153559770

Fax +l 2153552246

Email jhpdo@aol.com 
for adverse events. ${ }^{2}$ The Osteoarthritis Research Society International guidelines recommend topical NSAIDs as first-line therapy for patients with osteoarthritis and note that topical NSAIDs have equivalent efficacy and a lower frequency of adverse events compared with oral NSAIDs. ${ }^{12,13}$ The lower systemic availability of topical NSAIDs compared with oral NSAIDs ${ }^{14}$ may be the basis of the lower frequency of adverse events seen with topical NSAIDs in head-to-head comparisons with oral NSAIDs. ${ }^{15-18}$

Diclofenac sodium $1 \%$ gel (DSG) is a topical NSAID that is efficacious for the relief of osteoarthritis pain in the hand $^{19}$ and knee..$^{20,21}$ Data pooled from five randomized, placebo-controlled studies of 12 weeks' duration indicated that DSG was well tolerated in patients with hand or knee osteoarthritis who had an elevated risk of gastrointestinal, cardiovascular, or renal adverse events. ${ }^{22}$ The post hoc analysis reported here was conducted to determine the longterm tolerability of DSG in elderly patients and in patients with an elevated risk of gastrointestinal, cardiovascular, and renal adverse events.

\section{Methods and materials Study design}

This was a multicenter, open-label, long-term safety study that included patients who completed either of two primary 12-week studies (continuing patients) and others who were treatment-naive. ${ }^{23}$ Treatment-naive patients (males or nonpregnant females) were aged $\geq 35$ years and had radiographically confirmed mild to moderate (KellgrenLawrence grade 1-3) osteoarthritis of the knee, according to American College of Rheumatology criteria, for $\geq 6$ months before screening. ${ }^{24}$ Exclusion criteria for treatment-naive patients included current evidence or history of secondary osteoarthritis; history of rheumatoid arthritis, other chronic inflammatory disease, or fibromyalgia; allergy or asthma related to NSAIDs; evidence of peptic ulcer or history of gastrointestinal bleeding; significant injury to the target joint $\leq 30$ days before screening; major knee surgery at least one year before screening; or a significant medical condition that could compromise the patient's medical condition or confound study results, such as severe or uncontrolled renal, hepatic, hematologic, endocrine, cardiovascular, or neurologic disease. Scheduled visits occurred at baseline (the final visit of the primary study), monthly for 6 months, and at month 9. This completed one year of treatment in patients continuing from the active treatment groups in the doubleblind studies. Treatment-naive patients had an additional visit at month 12 .

\section{Treatment and assessments}

Patients applied $4 \mathrm{~g}$ of DSG to one or both knees for 9 months (for continuing patients) or 12 months (for treatment-naive patients). Rescue medication (acetaminophen, maximum $4 \mathrm{~g}$ daily) was allowed. All adverse events and serious adverse events were monitored and recorded. Standard laboratory analyses (hematology, blood chemistry, urine) were conducted every 3 months, and vital signs and general physical examination were assessed.

\section{Statistical analysis}

The incidence of adverse events was summarized in the alltreated patient population, which consisted of all patients who received at least one dose of DSG in a primary study or in the extension study. This included patients from the primary study who did not continue in the long-term safety study. Subpopulations comprised patients $<65$ and $\geq 65$ years of age, patients with or without hypertension, type 2 diabetes mellitus, cerebrovascular or cardiovascular disease, and patients with multiple comorbidities. Patients with multiple comorbidities were defined as those with combined diagnoses of hypertension, type 2 diabetes mellitus, and cerebrovascular or cardiovascular disease in their medical history. Because these populations were inadequately powered, only descriptive statistics were used for between-group comparisons.

\section{Results}

\section{Patients}

A total of 583 patients were enrolled in this extension study, which included 291 patients continuing from the primary studies and 292 treatment-naive patients (Figure 1). Of these 583 patients, 294 completed the study. ${ }^{23}$ Patient characteristics can be found in Table 1. Patients were 35-90 years of age. Most patients (64.2\%) were female.

The safety population consisted of 947 patients who received DSG or placebo during the 12-week studies or DSG during the extension study. This included 578 of the 583 patients enrolled in the extension study, as well as the 369 patients who received at least one dose of DSG in the primary studies but did not continue into the extension study. Five of the patients who enrolled in the extension study received no study drug and were not included in the safety population.

\section{Safety assessments}

\section{Stratification by age $<65$ years and $\geq 65$ years}

The safety population consisted of 575 patients $<65$ years of age and 372 patients $\geq 65$ years of age. The percentage of patients who experienced any adverse event was similar for 


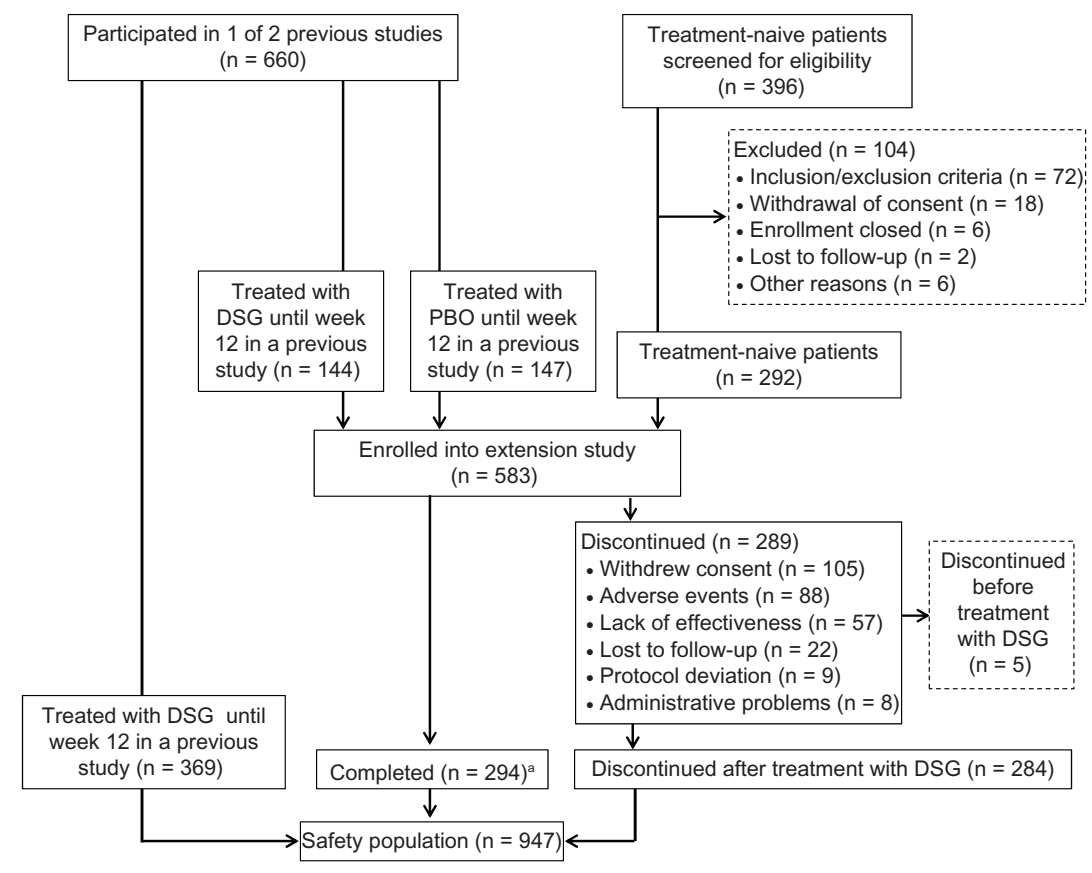

Figure I Patient disposition.

Notes: aStudy completion for each patient was decided by the investigator. For some patients, the final visit was too early to be included in the I2-month efficacy analysis. Abbreviations: DSG, diclofenac sodium I\% gel; PBO, placebo.

patients in both subgroups (Table 2). Patients aged $<65$ years were more likely to experience gastrointestinal adverse events and less likely to experience application site dermatitis compared with patients aged $\geq 65$ years.

\section{Stratification by comorbidity}

Almost half the patients (438/947; 46.3\%) had hypertension. However, just slightly more than $10 \%$ had type 2 diabetes mellitus $(100 / 947 ; 10.6 \%)$ and cerebrovascular or

Table I Patient characteristics

\begin{tabular}{|c|c|}
\hline Characteristic & $\begin{array}{l}\text { Study population } \\
(\mathrm{n}=947)\end{array}$ \\
\hline Mean (SD) age, years & $61.7(10.1)$ \\
\hline Range & $35-90$ \\
\hline Women, \% & 64.2 \\
\hline \multicolumn{2}{|l|}{ Race, \% } \\
\hline White & 82.5 \\
\hline Black & 11.0 \\
\hline Asian & 1.0 \\
\hline Other & 5.6 \\
\hline Mean (SD) BMI, kg/m² & $31.5(6.7)$ \\
\hline Range & $17.5-62.0$ \\
\hline Missing, n & 8 \\
\hline \multicolumn{2}{|c|}{$\begin{array}{l}\text { Adapted with permission from Peniston JH, Gold MS, Alwine LK. An open-label, long- } \\
\text { term safety and tolerability trial of diclofenac sodium } 1 \% \text { gel in patients with knee } \\
\text { osteoarthritis. Adapted from Phys Sportsmed. Volume 39;3I-38. Peniston JH, Gold MS, } \\
\text { Alwine LK. An open-label, long-term safety and tolerability trial of diclofenac sodium I\% } \\
\text { gel in patients with knee osteoarthritis. @ } 20 \mathrm{II} \text { with permission from JTE Multimedia. }\end{array}$} \\
\hline
\end{tabular}

cardiovascular disease $(97 / 947 ; 10.2 \%)$. The percentage of patients who experienced any adverse event (Table 3) was similar between patients with the comorbidities of hypertension, type 2 diabetes mellitus, or cerebrovascular or cardiovascular disease $(61.9 \%-65.5 \%)$ and slightly lower than the adverse event rates of patients without these comorbidities

Table 2 Total and most frequent adverse events stratified by age

\begin{tabular}{lll}
\hline AE, $\mathbf{n}$ (\%) & $\begin{array}{l}\text { Patients } \\
<\mathbf{6 5} \text { years } \\
(\mathbf{n}=\mathbf{5 7 5 )}\end{array}$ & $\begin{array}{l}\text { Patients } \\
\mathbf{6} \mathbf{6 5} \text { years } \\
\mathbf{( n = 3 7 2 )}\end{array}$ \\
\hline Any AE & $392(68.2)$ & $250(67.2)$ \\
Gastrointestinal AE & $54(9.4)$ & $25(6.7)$ \\
Cardiovascular AE & $19(3.3)$ & $12(3.2)$ \\
Application-site dermatitis & $50(8.7)$ & $49(13.2)$ \\
TEAEs reported in $\geq \mathbf{3 \%}$ of either age group & \\
Headache & $110(19.1)$ & $57(15.3)$ \\
Arthralgia & $77(13.4)$ & $55(14.8)$ \\
Back pain & $64(11.1)$ & $47(12.6)$ \\
Nasopharyngitis & $46(8.0)$ & $21(5.6)$ \\
Upper respiratory tract infection & $43(7.5)$ & $11(3.0)$ \\
Pain in extremity & $33(5.7)$ & $26(7.0)$ \\
Pain & $27(4.7)$ & $8(2.2)$ \\
Influenza & $27(4.7)$ & $7(1.9)$ \\
Sinusitis & $26(4.5)$ & $9(2.4)$ \\
Toothache & $18(3.1)$ & $4(1.1)$ \\
Sinus congestion & $18(3.1)$ & $1(0.3)$ \\
Myalgia & $17(3.0)$ & $9(2.4)$ \\
Neck pain & $10(1.7)$ & $13(3.5)$ \\
\hline
\end{tabular}

Abbreviations: AE, adverse event;TEAE, treatment-emergent adverse event. 
Table 3 Total and most frequent adverse events stratified by comorbidity

\begin{tabular}{|c|c|c|c|c|c|c|}
\hline AE, n (\%) & $\begin{array}{l}\text { With HTN } \\
(n=438)\end{array}$ & $\begin{array}{l}\text { Without HTN } \\
(n=509)\end{array}$ & $\begin{array}{l}\text { With T2DM } \\
(\mathrm{n}=100)\end{array}$ & $\begin{array}{l}\text { Without T2DM } \\
(n=847)\end{array}$ & $\begin{array}{l}\text { With C/CVD } \\
(n=97)\end{array}$ & $\begin{array}{l}\text { Without C/CVD } \\
(n=850)\end{array}$ \\
\hline Any AE & $287(65.5)$ & $355(69.7)$ & $64(64.0)$ & $587(68.2)$ & $60(61.9)$ & $582(68.5)$ \\
\hline Gastrointestinal AE & $39(8.9)$ & $40(7.9)$ & $7(7.0)$ & $72(8.5)$ & $12(12.4)$ & $67(7.9)$ \\
\hline Cardiovascular AE & $22(5.0)$ & $9(1.8)$ & $8(8.0)$ & $23(2.7)$ & $6(6.2)$ & $25(2.9)$ \\
\hline Application-site dermatitis & $36(8.2)$ & $63(12.4)$ & $10(10.0)$ & $89(10.5)$ & $8(8.2)$ & $91(10.7)$ \\
\hline \multicolumn{7}{|c|}{ TEAEs reported in $\geq 3 \%$ of any comorbidity group } \\
\hline Headache & $73(16.7)$ & $94(18.5)$ & $18(18.0)$ & $149(17.6)$ & $6(6.2)$ & I6I (18.9) \\
\hline Arthralgia & $70(16.0)$ & $62(12.2)$ & $7(7.0)$ & $125(14.8)$ & $14(14.4)$ & $118(13.9)$ \\
\hline Back pain & $52(11.9)$ & $59(11.6)$ & $12(12.0)$ & $99(11.7)$ & $7(7.2)$ & $104(12.2)$ \\
\hline Nasopharyngitis & $32(7.3)$ & $35(6.9)$ & $5(5.0)$ & $62(7.3)$ & $8(8.2)$ & $59(6.9)$ \\
\hline Pain in extremity & $31(7.1)$ & $28(5.5)$ & $6(6.0)$ & $53(6.3)$ & $4(4.1)$ & $55(6.5)$ \\
\hline Upper respiratory tract infection & $18(4.1)$ & $36(7.1)$ & $3(3.0)$ & $51(6.0)$ & $5(5.2)$ & $49(5.8)$ \\
\hline Pain & $16(3.7)$ & $19(3.7)$ & $2(2.0)$ & $33(3.9)$ & $2(2.1)$ & $33(3.9)$ \\
\hline Sinusitis & $15(3.4)$ & $20(3.9)$ & $3(3.0)$ & $32(3.8)$ & $3(3.1)$ & $32(3.8)$ \\
\hline Neck pain & $13(3.0)$ & $10(2.0)$ & $\mathrm{I}(\mathrm{I} .0)$ & $22(2.6)$ & $5(5.2)$ & $18(2.1)$ \\
\hline Rash & $13(3.0)$ & $6(1.2)$ & $3(3.0)$ & $16(1.9)$ & $3(3.1)$ & $16(1.9)$ \\
\hline Sinus congestion & $12(2.7)$ & $7(1.4)$ & $5(5.0)$ & $14(1.7)$ & $\mathrm{I}(\mathrm{I} .0)$ & $18(2.1)$ \\
\hline Contusion & II (2.5) & $8(1.6)$ & $4(4.0)$ & $15(1.8)$ & $5(5.2)$ & $14(1.6)$ \\
\hline Pharyngolaryngeal pain & $10(2.3)$ & $8(1.6)$ & $\mathrm{I}(\mathrm{I} .0)$ & $17(2.0)$ & $3(3.1)$ & I5 (I.8) \\
\hline Influenza & $8(1.8)$ & $26(5.1)$ & 0 & $34(4.0)$ & $4(4.1)$ & $30(3.5)$ \\
\hline Edema, peripheral & $6(1.4)$ & $8(1.6)$ & $5(5.0)$ & $9(1.1)$ & $3(3.1)$ & II (I.3) \\
\hline Pneumonia & $5(1.1)$ & $4(0.8)$ & $2(2.0)$ & $7(0.8)$ & $3(3.1)$ & $6(0.7)$ \\
\hline Myalgia & $4(0.9)$ & $22(4.3)$ & $I(I .0)$ & $25(3.0)$ & $3(3.1)$ & $23(2.7)$ \\
\hline Diabetes mellitus & $\mathrm{I}(0.2)$ & $2(0.4)$ & $3(3.0)$ & 0 & $\mathrm{I}(\mathrm{I} .0)$ & $2(0.2)$ \\
\hline Localized infection & $\mathrm{I}(0.2)$ & $4(0.8)$ & 0 & $5(0.6)$ & $3(3.1)$ & $2(0.2)$ \\
\hline
\end{tabular}

Abbreviations: AE, adverse event; C/CVD, cerebrovascular or cardiovascular disease; HTN, hypertension; T2DM, type 2 diabetes mellitus; TEAE, treatment-emergent adverse event.

(68.2\%-69.7\%). The percentage of patients experiencing gastrointestinal adverse events was similar among patients with comorbid conditions of hypertension, type 2 diabetes mellitus, or cerebrovascular or cardiovascular disease $(7.0 \%-12.4 \%)$ and generally similar to gastrointestinal adverse event rates in patients without these conditions (7.9\%-8.5\%). Patients with hypertension, type 2 diabetes mellitus, or cardiovascular disease experienced similar rates of cardiovascular adverse events (5.0\%-8.0\%). Slightly lower cardiovascular adverse event rates $(1.8 \%-2.9 \%)$ were observed in patients without these comorbid conditions. Application site dermatitis occurred at rates of $8.2 \%$ to $12.4 \%$ among the comorbidity subgroups and the three corresponding groups without comorbidities.

Only $1.6 \%$ of patients $(15 / 947)$ in the safety population had all three comorbid conditions. No patients in this multiple comorbidity subgroup had gastrointestinal adverse events or application site dermatitis (Table 4). Cardiovascular adverse events (atrial fibrillation and hypertension) were experienced by $13.3 \%$ (2/15) of patients in the multiple comorbidity subgroup compared with $3.1 \%$ in the other 932 patients.

\section{Discussion}

This post hoc analysis was conducted following long-term treatment of patients with knee osteoarthritis to assess the tolerability of DSG treatment in patient subpopulations with an elevated risk of developing adverse events related to NSAID therapy. Subgroup analyses indicated that DSG was well tolerated in patients $\geq 65$ years of age; in patients with comorbid hypertension, type 2 diabetes mellitus, or cerebrovascular or cardiovascular disease; and even in patients with diagnoses of all three comorbidities combined. The frequency of any adverse event was not increased in these subpopulations compared with patients $<65$ years of age or patients without these comorbid conditions. However, application site dermatitis was more frequently reported among patients $\geq 65$ years of age compared with patients $<65$ years of age.

Knee osteoarthritis is a condition that occurs commonly among individuals aged $\geq 65$ years $^{25}$ and frequently requires medical intervention. Therapy for patients with osteoarthritis must balance pain relief and potential treatment-related side effects. This may be particularly challenging in patients who are predisposed to these adverse events, such as the elderly. Although NSAIDs are able to provide analgesia 
Table 4 Total and most frequent adverse events stratified by multiple comorbidities*

\begin{tabular}{|c|c|c|}
\hline AE, n (\%) & $\begin{array}{l}\text { With } \\
\text { MultiCom } \\
(n=15)\end{array}$ & $\begin{array}{l}\text { Without } \\
\text { MultiCom } \\
(n=932)\end{array}$ \\
\hline Any AE & $8(53.3)$ & $634(68.0)$ \\
\hline Gastrointestinal $\mathrm{AE}$ & 0 & $79(8.5)$ \\
\hline Cardiovascular AE & $2(13.3)$ & $29(3.1)$ \\
\hline Application-site dermatitis & 0 & $99(10.6)$ \\
\hline \multicolumn{3}{|c|}{ TEAEs reported in $\geq 3 \%$ of either group } \\
\hline Headache & I (6.7) & $166(17.8)$ \\
\hline Arthralgia & $3(20.0)$ & $129(13.8)$ \\
\hline Back pain & 0 & $111(11.9)$ \\
\hline Nasopharyngitis & 0 & $67(7.2)$ \\
\hline Pain in extremity & 0 & $59(6.3)$ \\
\hline Upper respiratory tract infection & 0 & $54(5.8)$ \\
\hline Pain & 0 & $35(3.8)$ \\
\hline Sinusitis & $2(13.3)$ & $33(3.5)$ \\
\hline Neck pain & I (6.7) & $22(2.4)$ \\
\hline Hypertension & I (6.7) & $10(1.1)$ \\
\hline Influenza & 0 & $34(3.6)$ \\
\hline Edema, peripheral & $\mathrm{I}(6.7)$ & $13(1.4)$ \\
\hline Pneumonia & I (6.7) & $8(0.9)$ \\
\hline Application-site erythema & I (6.7) & $8(0.9)$ \\
\hline Myalgia & I (6.7) & $25(2.7)$ \\
\hline Dyspnea & I (6.7) & $6(0.6)$ \\
\hline Pruritus & I (6.7) & $5(0.5)$ \\
\hline Cough & I (6.7) & II (I.2) \\
\hline Atrial fibrillation & $\mathrm{I}(6.7)$ & $\mathrm{I}(0 . \mathrm{I})$ \\
\hline Dental caries & I (6.7) & $2(0.2)$ \\
\hline Muscle spasms & I (6.7) & $7(0.8)$ \\
\hline Pharyngitis streptococcal & I (6.7) & $\mathrm{I}(0 . \mathrm{I})$ \\
\hline Application-site papules & I (6.7) & $\mathrm{I}(0 . \mathrm{I})$ \\
\hline Diabetes mellitus & I (6.7) & $2(0.2)$ \\
\hline Epistaxis & I (6.7) & 0 \\
\hline Ligament disorder & I (6.7) & 0 \\
\hline
\end{tabular}

Note: *Hypertension and type 2 diabetes mellitus and cerebrovascular or cardiovascular disease.

Abbreviations: $\mathrm{AE}$, adverse event; MultiCom, multiple comorbidities; TEAE, treatment-emergent adverse event.

for osteoarthritis, the age-related risks of gastrointestinal, ${ }^{3-5}$ cardiovascular, ${ }^{6,7}$ and renal ${ }^{8-10}$ adverse events effectively limit the usefulness of this drug class. Cardiovascular disease ${ }^{26}$ as well as gastrointestinal disorders ${ }^{27}$ occur at a higher frequency in the elderly. Medications used to treat comorbid conditions in the elderly have the potential to interact with NSAIDs, further increasing the risk of adverse events. ${ }^{28}$ Topical NSAIDs, such as DSG, can provide local pain relief as effectively as oral NSAIDs, ${ }^{16,18}$ presumably with more limited systemic exposure, thus reducing the risk of adverse events.

An earlier analysis of pooled data from patients treated for 12 weeks with DSG indicated that the occurrence of most adverse events was similar in patients $\geq 65$ years of age compared with patients $<65$ years of age. ${ }^{22}$ In that analysis, a higher percentage of patients aged $\geq 65$ years $(8.8 \%)$ reported application site dermatitis, compared with patients aged $<65$ years $(5.6 \%) .{ }^{22}$ The percentage of patients experiencing adverse events who had hypertension, type 2 diabetes mellitus, or cerebrovascular or cardiovascular disease was similar compared with patients who did not have these comorbid conditions. ${ }^{22}$ The post hoc analysis reported here extends the results of that study and indicates that DSG may be safely used over a longer period to treat knee osteoarthritis in patients at higher risk for the development of adverse events.

The overall rate of adverse events was not increased in patients with hypertension, type 2 diabetes mellitus, or cerebrovascular or cardiovascular disease compared with patients without these comorbidities. Likewise, rates of gastrointestinal adverse events and application site dermatitis were not influenced by the presence of the comorbid conditions. The incidence of cardiovascular adverse events was somewhat higher in patients with these comorbidities, but this is not surprising considering the well known associations between hypertension, type 2 diabetes mellitus, and cerebrovascular or cardiovascular disease, and the risk of experiencing an adverse cardiovascular event. Given that the American Heart Association advises caution when using NSAIDs in patients with elevated cardiovascular risk, ${ }^{6}$ the favorable tolerability of DSG in patients with multiple comorbidities and associated elevated cardiovascular risk is of particular clinical relevance. It is especially important that DSG was well tolerated by the 15 patients with combined diagnoses of all three comorbid conditions. This triad of disorders would include patients with metabolic syndrome (a constellation of cardiovascular risk factors defined by World Health Organization as glucose intolerance, impaired glucose tolerance, and/or type 2 diabetes mellitus plus two of the following: central obesity, raised plasma triglycerides and/or low HDL-cholesterol, raised arterial pressure, insulin resistance, microalbuminuria, or impaired glucose regulation ${ }^{29}$ ). The incidence of metabolic syndrome is increased in patients with osteoarthritis. ${ }^{30}$

This post hoc analysis was limited by the small sample size of a number of the subgroups, particularly patients with type 2 diabetes mellitus or cerebrovascular or cardiovascular disease and those in the multiple comorbidity group, thus precluding statistical testing of differences in tolerability between subgroups. Also, the protocol of the original study excluded patients with serious or unstable illness; thus, some patients seen in clinical practice with hypertension, type 2 diabetes mellitus, and cerebrovascular or cardiovascular disease may be more ill than those studied in this post hoc analysis. Further studies would be of value that specifically enroll patients with these comorbidities and do not exclude 
those with more serious illness. The patients in this study were treated for knee osteoarthritis, and the results cannot be extended to patients with osteoarthritis of the hand or other areas. Another limitation is the absence of comparator groups treated with placebo or an oral NSAID. Nevertheless, this study provides clinically relevant data that are important for patients with osteoarthritis of the knee and the physicians who treat them.

\section{Conclusion}

The results reported here suggest that long-term DSG treatment is safe in patient subpopulations with an elevated risk of NSAID-related adverse events. DSG may be safely administered as long-term therapy in elderly patients with knee osteoarthritis and in patients with comorbid conditions that predispose them to NSAID-related adverse events.

\section{Disclosure}

This research was supported by Novartis Consumer Health Inc, Parsippany, NJ, and Endo Pharmaceuticals Inc, Chadds Ford, PA. MSG is an employee of Novartis Consumer Health Inc, and MSW is an employee of Endo Pharmaceuticals Inc. Editorial support was provided by Daniel McCallus, $\mathrm{PhD}$, and Robert Gatley, MD, of Complete Healthcare Communications, Inc, Chadds Ford, PA, and was funded by Endo Pharmaceuticals Inc.

\section{References}

1. Bateman DN, Kennedy JG. Non-steroidal anti-inflammatory drugs and elderly patients. BMJ. 1995;310:817-818.

2. Zhang W, Moskowitz RW, Nuki G, et al. OARSI recommendations for the management of hip and knee osteoarthritis, part II: OARSI evidence-based, expert consensus guidelines. Osteoarthritis Cartilage. 2008;16:137-162.

3. Boers M, Tangelder MJ, van Ingen H, Fort JG, Goldstein JL. The rate of NSAID-induced endoscopic ulcers increases linearly but not exponentially with age: a pooled analysis of 12 randomised trials. Ann Rheum Dis. 2007;66:417-418.

4. Franceschi M, Di Mario F, Leandro G, Maggi S, Pilotto A. Acidrelated disorders in the elderly. Best Pract Res Clin Gastroenterol. 2009;23:839-848.

5. Richy F, Bruyere O, Ethgen O, et al. Time dependent risk of gastrointestinal complications induced by non-steroidal anti-inflammatory drug use: a consensus statement using a meta-analytic approach. Ann Rheum Dis. 2004;63:759-766.

6. Antman EM, Bennett JS, Daugherty A, et al. Use of nonsteroidal antiinflammatory drugs: an update for clinicians: a scientific statement from the American Heart Association. Circulation. 2007;115: 1634-1642.

7. Motsko SP, Rascati KL, Busti AJ, et al. Temporal relationship between use of NSAIDs, including selective COX-2 inhibitors, and cardiovascular risk. Drug Saf. 2006;29:621-632.

8. Barkin RL, Buvanendran A. Focus on the COX-1 and COX-2 agents: renal events of nonsteroidal and anti-inflammatory drugs-NSAIDs. $\mathrm{Am}$ J Ther. 2004;11:124-129.
9. Huerta C, Castellsague J, Varas-Lorenzo C, Garcia Rodriguez LA. Nonsteroidal anti-inflammatory drugs and risk of ARF in the general population. Am J Kidney Dis. 2005;45:531-539.

10. Whelton A. Nephrotoxicity of nonsteroidal anti-inflammatory drugs: physiologic foundations and clinical implications. Am JMed. 1999;106: $13 \mathrm{~S}-24 \mathrm{~S}$.

11. Huerta C, Varas-Lorenzo C, Castellsague J, Garcia Rodriguez LA. Non-steroidal anti-inflammatory drugs and risk of first hospital admission for heart failure in the general population. Heart. 2006;92:1610-1615.

12. Zhang W, Doherty M, Leeb BF, et al. EULAR evidence based recommendations for the management of hand osteoarthritis: report of a Task Force of the EULAR Standing Committee for International Clinical Studies Including Therapeutics (ESCISIT). Ann Rheum Dis. 2007;66:377-388.

13. Zhang W, Nuki G, Moskowitz RW, et al. OARSI recommendations for the management of hip and knee osteoarthritis, part III: changes in evidence following systematic cumulative update of research published through January 2009. Osteoarthritis Cartilage. 2010;18:476-499.

14. Kienzler J, Gold M, Nollevaux F. Systemic bioavailability of topical diclofenac sodium gel $1 \%$ versus oral diclofenac sodium in healthy volunteers. J Clin Pharmacol New Drugs. 2010;50:50-61.

15. Sandelin J, Harilainen A, Crone H, et al. Local NSAID gel (eltenac) in the treatment of osteoarthritis of the knee. A double blind study comparing eltenac with oral diclofenac and placebo gel. Scand J Rheumatol. 1997;26:287-292.

16. Tugwell PS, Wells GA, Shainhouse JZ. Equivalence study of a topical diclofenac solution (Pennsaid) compared with oral diclofenac in symptomatic treatment of osteoarthritis of the knee: a randomized controlled trial. J Rheumatol. 2004;31:2002-2012.

17. Zacher J, Burger KF, Farber L. Topical diclofenac Emulgel versus oral ibuprofen in the treatment of active osteoarthritis of the finger joints (Heberden's and/or Bouchard's nodes). Double-blind, controlled, randomized study. Aktuelle Rheumatologie. 2001;26:7-14. German.

18. Simon LS, Grierson LM, Naseer Z, Bookman AA, Zev Shainhouse J. Efficacy and safety of topical diclofenac containing dimethyl sulfoxide (DMSO) compared with those of topical placebo, DMSO vehicle and oral diclofenac for knee osteoarthritis. Pain. 2009;143:238-245.

19. Altman RD, Dreiser RL, Fisher CL, et al. Diclofenac sodium gel in patients with primary hand osteoarthritis: a randomized, double-blind, placebo-controlled trial. J Rheumatol. 2009;36:1991-1999.

20. Baraf HS, Gold MS, Clark MB, Altman RD. Safety and efficacy of topical diclofenac sodium 1\% gel in knee osteoarthritis: a randomized controlled trial. Phys Sportsmed. 2010;38:19-28.

21. Barthel HR, Haselwood D, Longley S 3rd, Gold MS, Altman RD. Randomized controlled trial of diclofenac sodium gel in knee osteoarthritis. Semin Arthritis Rheum. 2009;39:203-212.

22. Baraf HS, Gold MS, Petruschke RA, Wieman MS. Tolerability of topical diclofenac sodium $1 \%$ gel for osteoarthritis in seniors and patients with comorbidities. Am J Geriatr Pharmacother. 2012;10:47-60.

23. Peniston JH, Gold MS, Alwine LK. An open-label, long-term safety and tolerability trial of diclofenac sodium 1\% gel in patients with knee osteoarthritis. Phys Sportsmed. 2011;39:31-38.

24. Altman R, Alarcón G, Appelrouth D, et al. The American College of Rheumatology criteria for the classification and reporting of osteoarthritis of the hand. Arthritis Rheum. 1990;33:1601-1610.

25. Dawson J, Linsell L, Zondervan K, et al. Epidemiology of hip and knee pain and its impact on overall health status in older adults. Rheumatology (Oxford). 2004;43:497-504.

26. Rosamond W, Flegal K, Friday G, et al. Heart disease and stroke statistics - 2007 update: a report from the American Heart Association Statistics Committee and Stroke Statistics Subcommittee. Circulation. 2007;115:e69-e171.

27. Higham J, Kang JY, Majeed A. Recent trends in admissions and mortality due to peptic ulcer in England: increasing frequency of haemorrhage among older subjects. Gut. 2002;50:460-464. 
28. Tulner LR, Frankfort SV, Gijsen GJ, et al. Drug-drug interactions in a geriatric outpatient cohort: prevalence and relevance. Drugs Aging 2008;25:343-355.

29. World Health Organozation. Definition, Diagnosis and Classification of Diabetes Mellitus and its Complications. Report of a WHO Consultation. Geneva, Switzerland: World Health Organization; 1999.
30. Puenpatom RA, Victor TW. Increased prevalence of metabolic syndrome in individuals with osteoarthritis: an analysis of NHANES III data. Postgrad Med. 2009;121:9-20.

\section{Publish your work in this journal}

Clinical Interventions in Aging is an international, peer-reviewed journal focusing on evidence-based reports on the value or lack thereof of treatments intended to prevent or delay the onset of maladaptive correlates of aging in human beings. This journal is indexed on PubMed Central, MedLine, the American Chemical Society's 'Chemical Abstracts

\section{Dovepress}

Service' (CAS), Scopus and the Elsevier Bibliographic databases. The manuscript management system is completely online and includes a very quick and fair peer-review system, which is all easy to use. Visit $\mathrm{http}: / /$ www.dovepress.com/testimonials.php to read real quotes from published authors.

Submit your manuscript here: http://www.dovepress.com/clinical-interventions-in-aging-journal 